\title{
High Performance Liquid Chromatographic Identification and Estimation of Phthalates in Sewer Waste and a Receiving River in Ibadan City, Southwestern Nigeria
}

\author{
Gregory O. Adewuyi \\ Department of Chemistry, University of Ibadan, Ibadan, Nigeria \\ Email: adewuyio@yahoo.co.uk
}

Received August 2, 2012; revised September 1, 2012; accepted October 2, 2012

\begin{abstract}
Medical wastes have been implicated in river pollution in developing countries and most often people depend on water from such rivers for sources of livelihood. Phthalates (endocrine disruptors) are major components in medical wastes and are commonly found contaminants in aquatic environment. Most sewage treatment facilities handling medical waste are inefficient due to overuse and poor maintenance and discharge directly into rivers. This study aimed to investigate the identity and estimates the concentration of phthalates in supposed treated medical wastes from a hospital sewer and water from a receiving river. Samples were randomly collected before and after treatment by the sewer plants, while samples were randomly collected along the course of the river starting from point of discharge. Control samples were taken from upstream about $500 \mathrm{~m}$ along the river course. The samples were extracted by liquid-liquid chromatographic process using dichloromethane, after which they were cleaned up in a column of silica gel using hexane as the mobile solvent. The cleaned extracts were analyzed by HPLC. The concentrations $(\mu \mathrm{g} / \mathrm{L})$ of dimethyl-, diethyl-, diphenyl-, dibutyl- and di-(2-ethyl)hexyl phthalates ranged from $62.81 \pm 18.53 ; 4.74 \pm 3.57$; $2.05 \pm 1.80 ; 11.40 \pm 5.58$ to $141.92 \pm 35.8$ respectively in the sewer waste. The receiving river had a concentration $(\mu \mathrm{g} / \mathrm{L})$ of $9.17 \pm 14.02 ; 0.18 \pm$ 0.31; $0.48 \pm 0.84 ; 2.84 \pm 1.21$; $61.72 \pm 38.35$ respectively for dimethyl-, diethyl-, diphenyl-, dibutyl- and di-(2-ethyl) hexyl phthalates. These concentrations were higher than control and far exceeded the USEPA limits of $3 \mu \mathrm{g} / \mathrm{l} \mathrm{recom-}$ mended for phthalates in water. Contaminants of aquatic environment by untreated wastes from hospitals has serious implications on public health and environment as human risks for phthalate esters downstream are high and this calls for urgent need to develop strategy to build incentives for compliance in treatment and discharge of wastes into river waters.
\end{abstract}

Keywords: Sewage Treatment; Phthalates; Liquid-Liquid Extraction; Clean-Up; Effluent; Toxicity

\section{Introduction}

The impact of some synthetic industrial chemicals on environment has attracted a lot of attention worldwide due to their overwhelming environmental significance. In the last five decades, there has been a growing interest and concern on the study of the impacts of some of these chemicals especially phthalate esters on wild-life, humans and the environment. Phthalate esters are dialkyl- or alkyl/aryl esters of 1,2-benzenedicarboxylic acid (phthalic acid); they have a myriad of commercial uses and are considered ubiquitous environmental contaminants. Globally over 8 billion tones of phthalate esters are used each year primarily as additives to poly (vinyl) chloride plastics, as industrial solvents and as components of many consumer products [1]. Phthalates have been implicated as possible carcinogenic or tetratogenic agents for humans [2-4]. Some other well documented human health problems in which phthalate esters are implicated include early puberty in girls [5], genital defects and reduced testosterone production [6,7], testicular cancer impaired sperm quality and sperm damage in men $[6,8,9]$, premature delivery $[8,10]$ respiratory health problems like air obstruction, lung malfunction [11] and asthma [12,13].

However, it is the possible action of phthalates as endocrine disrupters in humans that has caused the most serious concern [5,14-16]. In most of the compounds that utilizes phthalates, they are not chemically bound to the matrix, and hence they can easily diffuse or leach out into the environment overtime $[17,18]$. The general population is exposed to phthalates through consumer products as well as through diet and medical treatments [19]. One of the main routes of exposure is via water; also, these chemicals find their ways into rivers through effluent discharges, leaching from waste dumps and 
through diffuse sources [20]. The potential health risk of exposure to phthalates is higher in the developing countries considering the fact that waters for domestic activities are sourced directly from streams with little or no treatment. Considering the widespread use of polyvinylchloride medical devices in the healthcare delivery services, hospital sewage is therefore highly susceptible to contain high level of phthalate esters [21]. Most hospitals hardly treat their effluents before discharge into surrounding water bodies. Though liquid waste from University College Hospital in Ibadan are channelled into a sewage plant before the effluents are discharged directly into a receiving river that serves as the major source of water to some local populations who use the water for domestic, irrigational and recreational activities. Therefore, for the purpose of establishing the effectiveness of the sewage treatment plant, this paper aims at determining the levels of phthalate esters in the supposedly treated hospital effluents and in the waters of the receiving river using high performance liquid chromatography.

\section{Materials and Methods}

\subsection{Reagents and Standards}

All chemicals used in this study were of analytical reagent grade. Acetonitrile, n-hexane, and ethyl acetate were of HPLC grade. All solvents were further purified by distillation. Phthalate esters and n-butyl benzoate were purchased from Merck and Aldrich Chemical Company. Organic free water was sourced from International Institute for Tropical Agriculture, Ibadan. Sodium chloride, sodium carbonate, anhydrous sodium sulphate and alumi- nium oxide; were purified by heating in a muffle furnace at $450^{\circ} \mathrm{C}$ for 4 hours.

\subsection{Description of the Study Area}

The sampling areas were the sewage treated plant of the University College Hospital, Ibadan where the effluent samples were collected and Olojuoro river in Ibadan city which receives the effluents discharges. The sewage system, as indicated on the map (Figure 1), receives waste waters and sewage from the school of nursing staff residential quarters, hall of residence, the hospital complex and the farm. These are collected together in the collecting box, the grits and other settleable solids settle under gravitational action to form the sludge in the sedimentation tank. The sewage receives no further treatment, except that it is dozed with chlorine before it is finally discharged into Olojuoro river.

\subsection{Sampling}

The effluents from the sewage plant were sampled in three different designated sampling points $\mathrm{S}_{1}-\mathrm{S}_{3}$ of about $10 \mathrm{~m}$ apart, as shown in Figure 1. The receiving stream was similarly sampled, but with more sampling points $\left(\mathrm{S}_{4}-\mathrm{S}_{7}\right)$ from the point of discharge of the effluent and downstream, this method has been adjudged as the most effective way of monitoring point source pollution in water bodies.

Amber bottles were used for sampling to prevent bacteria growth. All bottles and other glassware used for sampling were thoroughly washed and soaked in chromic acid as described by [22], the bottles were rinsed seve-

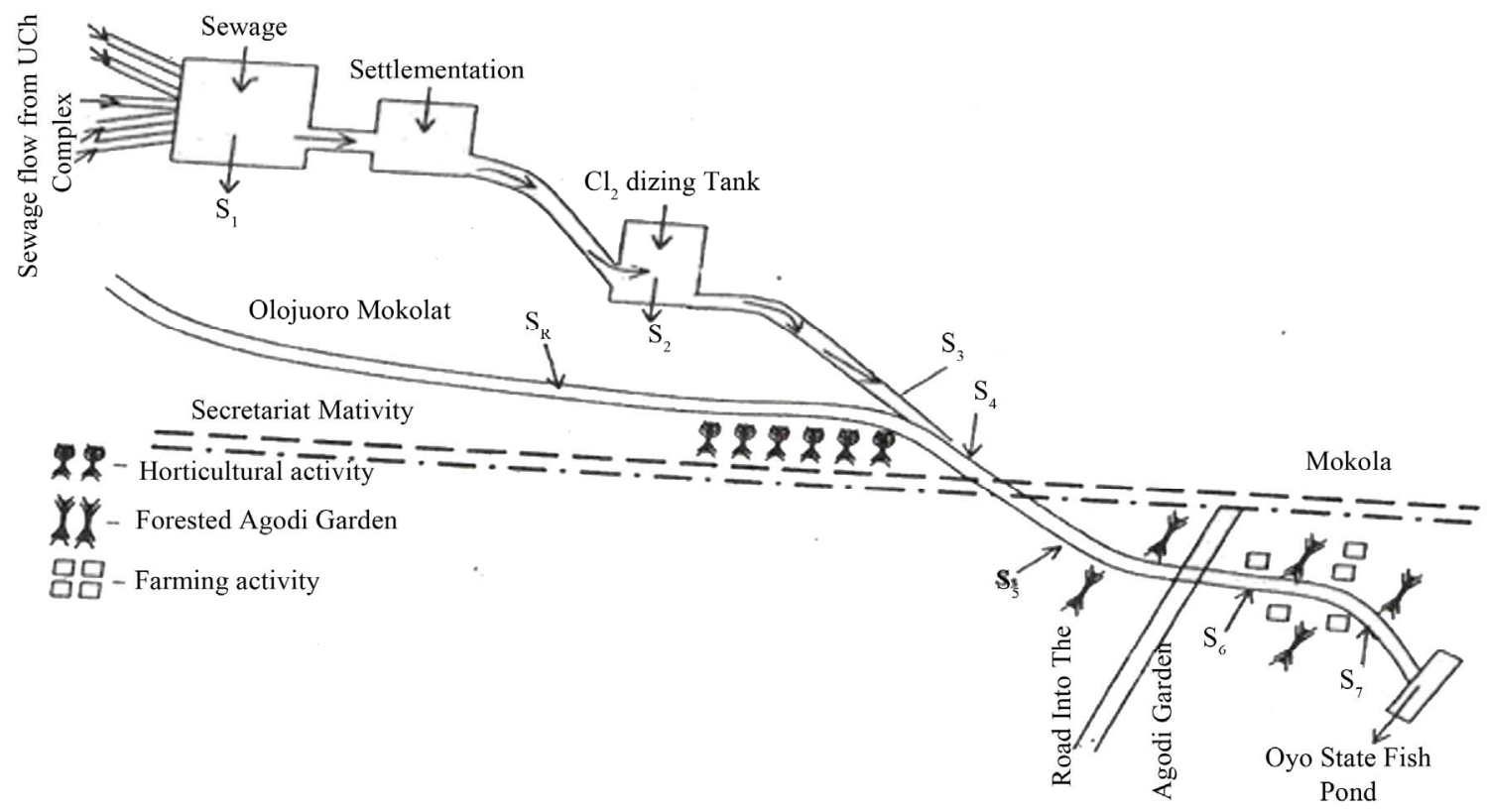

Figure 1. Description of the study areas. 
rally with organic free water. Bottles were dried in oven for 2 hrs at $105^{\circ} \mathrm{C}$ and finally rinsed with dichloromethane (DCM) before employed for sampling. Sampling locations were as indicated on the map (Figure 1). Samples were collected once every week for six weeks (from the third week of the month of January to the end of the month of February 2009). The samples $S_{1}-S_{3}$ are sewage samples. Sample $S_{R}$ is the reference sample collected from the receiving stream, at a point, about $20 \mathrm{~m}$ upstream from the point of effluent discharge into the stream. Samples $S_{4}-S_{7}$ are samples from the stream from few metres away from the point of effluent discharge into the stream until the stream enters the Oyo State fishpond. These samples were collected at about $20 \mathrm{~m}$ apart. The sample bottles were first rinsed with samples before final collection. The $\mathrm{pH}$ of the samples was immediately adjusted to 2 by the addition of concentrated hydrochloric acid after collection; this was to reduce the activity of microorganisms. Samples were collected to the brim of the bottles and covered with metal caps. Thereafter samples were stored in ice bucket and transported to the laboratory for analysis.

\subsection{Extraction Procedures}

Cold liquid extraction procedure was used for this experiment. $500 \mathrm{ml}$ of the sample was measured into a separatory funnel. The sample was saturated with about $10 \mathrm{~g}$ of sodium chloride to prevent the formation of persistent emulsions from the solvent [23]. It was then extracted with three portions of $25 \mathrm{ml}$ dichloromethane. The three portions of extracts from each sample were added together in another separatory funnel. Free-fatty acid interferences from the organic constituents were removed by further extraction with $5 \times 10 \mathrm{ml} 0.1 \mathrm{M}$ sodium carbonate [24]. The extracts were then dried over anhydrous sodium sulphate in a glass fibre filter $[25,26]$. The solvent was evaporated using rotary evaporator, after which the residue was re-dissolved in $2 \mathrm{ml}$ of dichloromethane for clean-up process.

\section{Clean-Up Procedure}

About $12.5 \mathrm{~g}$ of activated alumina prepared in a slurry form with n-hexane was packed in a column of about 10 $\mathrm{ml}$. The extract was chromatographed through the packed column. Hydrocarbons and phthalate esters were eluted successively from the column with $20 \mathrm{ml}$ of n-hexane and $30 \mathrm{ml}$ ethyl acetate. The ethyl acetate eluate was concentrated to $1 \mathrm{ml}$ by purging with nitrogen gas. $1 \mathrm{ml}$ of acetonitrile was added to the residue for HPLC analysis [24-26]. The extracts were kept in refrigerator below 4\% until instrumental analysis was conducted.

\subsection{Instrumental Analysis}

High performance liquid chromatographic analysis was carried out with Hellanco series HPLC system available at the Department of Chemistry, Laboratory of Analytical Chemistry, University of Athens, Athens Greece. The instrument was equipped with a degasser, a quaternary pump, an autosampler, ultra violet and fluorescence detector, a thermostated column compartment, variable wavelength detector and a computer system. Chromatographic separation was carried out using a $150 \mathrm{~mm} \times 4.6$ mm i.d. Zorbax Eclipse $\mathrm{XDB}_{18}$ analytical column with particle size of $5 \mu \mathrm{m}$. Detection of phthalate ester was done at $226 \mathrm{~nm}$ wavelength. Chromatographic separation was performed under gradient elution condition using acetonitrile and water $(80: 20 \mathrm{v} / \mathrm{v})$ as mobile phase. Under these condition separation lasted for about 18 minutes with flow rate of $0.3 \mathrm{~m} 1 / \mathrm{min}$. $20 \mu \mathrm{l}$ was used as the injection volume and the column temperature was set at $40^{\circ} \mathrm{C}$. Identification of phthalate ester was based on its retention time and quantification was by combination of internal standardization and response factor. Individual phthalate esters in the standard mixture and samples were identified according to their retention times.

\subsection{Preparation of Stock Standard Solution and Determination of Response Factors}

A stock solution $(100 \mathrm{mg} / \mathrm{L})$ of the mixture of the pure phthalate ester analyte standards and n-butyl benzoate internal standards was prepared by weighing out $1.0 \mathrm{mg}$ each of the phthalate ester standards and internal standards into the same container, and making up to $10 \mathrm{~mL}$ mark with acetonitrile. This solution was run on high performance liquid chromatography for the determination of response factor for the respective phthalate esters using the expression shown below [20].

Response Factor $=$ Peak Area of Phthalate/Peak area of Internal Standard.

\subsection{Recovery Studies and Quality Assurance}

Preparation of sampling materials, sampling procedures, reagents and materials, extraction and analytical procedures were carefully quality controlled. Quality assurance study was carried out in terms of recoveries of phthalate in order to ascertain the efficiency of the extraction and the analytical procedures since no certified reference material was available. The recovery study was carried out to assess the efficiency of the methodology. The recovery study was carried out by blank water samples spiked with known concentration of mixture of dimethyl-, diethyl-, diphenyl-, dibutyl- and diethylhexyl phthalates.

\section{Results and Discussion}

The efficiency and suitability of the analytical procedure was assessed in terms of recovery and sensitivity. Using 
high performance liquid chromatography with gradient elution, the phthalates were eluted from the column in the order of dimethyl-, diethyl-, diphenyl-, dibutyl, and di-(2-ethyl hexyl) phthalates. The $\mathrm{R}_{\mathrm{f}}$ values are as indicated in Table 1. This elution pattern was similar to the observations of [20] and [24]. The recovery study was used to establish the efficiency of the procedure adopted in this work. The percentage recoveries ranged from 57.48 to 96.95 for the phthalates (Table 1). The range of the result is comparable to percentage recoveries obtained in some previous works on phthalates which were $46.36 \%$ - 71.5\% [24], 23.78\% - 85.5\% [25] and 50\% - 105\% [27]. These comparable results further establish the validity of the recovery study and confirmed the efficiency of the analytical procedure adopted for this work.

The values for response factor of the detector as determined using the mixture of phthalates standards and the limits of detection were recorded in Table 1. The limits of detection were calculated as twice the standard deviation of peak areas of respective phthalates for ten runs on the high performance liquid chromatography [28]. The very low values obtained for limits of detection confirm the high sensitivity of the analytical procedure adopted for the study. In this study, phthalates were not detected in the uncontaminated water (organic free water) blank. This equally confirmed that problems relating to background contamination that have been identified as major flaws in the liquid phase analysis of phthalates [20] has been adequately solved. A representative chromatogram of phthalates standards and the internal standard is shown in Figure 2. The peaks are well resolved which makes it easy for identification of the phthalates in the sample.

The results of quantitative analysis of phthalates in designated sampling points which included sewage effluents, receiving stream and reference samples for a period of six weeks (third week of the month January to the end of the month of February) are presented in Table 2. The levels established in this study showed wide occurrence of phthalates in both the sewage effluents and the receiving stream samples.

A total of five phthalate esters were identified in the sewage effluents and the receiving stream. The prominent phthalate esters detected during the period of this study in order of prominence were diethylhexyl-, dimethyl-, dibutyl phthalates. Diphenyl-, diethyl phthalates levels are extremely low in most samples especially the receiving stream (Figure 3).

A cursory look at the concentrations of phthalate esters in the reference samples, $S_{R}$, (Table 2) shows the ubiquity of phthalate esters in the environment. The mean concentrations of the phthalate esters ranged from not detected to $2.69 \mu \mathrm{g} / \mathrm{L}$. The background presence of the detected phthalates in the reference samples may be attributed to background contamination of the stream by
Table 1. Values for response factor, retention time and recovery of phthalate esters from spiked samples.

\begin{tabular}{ccccc}
\hline $\begin{array}{c}\text { Phthalate } \\
\text { esters }\end{array}$ & $\begin{array}{c}\text { Responses } \\
\text { factors }\end{array}$ & $\begin{array}{c}\text { Retention } \\
\text { times }(\mathrm{min})\end{array}$ & \% Recovery & $\begin{array}{c}\text { Limit of detection } \\
(\mu \mathrm{g} / \mathrm{L})\end{array}$ \\
\hline DMP & 0.62 & 7.23 & 89.02 & 0.87 \\
DEP & 0.56 & 8.26 & 77.93 & 0.98 \\
DPhP & 0.6 & 10.09 & 57.48 & 1.23 \\
DBP & 0.48 & 13.2 & 83.5 & 1.02 \\
DEHP & 0.53 & 16.45 & 96.95 & 0.60 \\
\hline
\end{tabular}

Table 2. Mean levels of phthalates in the sampled sites.

\begin{tabular}{lccccc}
\hline SP $^{*}$ & DMP & DEP & DPhP & DBP & DEHP \\
\hline SR & ND & ND & $0.97 \pm 1.27$ & $1.99 \pm 1.69$ & $2.69 \pm 1.14$ \\
S1 & $48.69 \pm 8.16$ & $9.78 \pm 3.13$ & $4.57 \pm 3.47$ & $12.95 \pm 4.90$ & $93.09 \pm 24.29$ \\
S2 & $50.74 \pm 8.02$ & $2.34 \pm 1.97$ & ND & $3.92 \pm 3.38$ & $154.52 \pm 35.06$ \\
S3 & $88.99 \pm 16.962 .11 \pm 1.86$ & $1.57 \pm 1.27$ & $17.32 \pm 4.62$ & $178.17 \pm 50.70$ \\
S4 & $33.40 \pm 13.22$ & ND & $1.93 \pm 1.33$ & $4.37 \pm 1.34$ & $127.47 \pm 42.35$ \\
S5 & ND & ND & ND & $3.63 \pm 0.59$ & $35.82 \pm 9.35$ \\
S6 & $0.72 \pm 0.91$ & $2.44 \pm 1.29$ & $1.94 \pm 0.77$ & ND & $48.68 \pm 8.24$ \\
S7 & $0.83 \pm 0.98$ & ND & ND & $1.41 \pm 1.57$ & $34.92 \pm 9.84$ \\
\hline
\end{tabular}

Concentrations are mean values \pm standard deviation for $\mathrm{n}=6$; $\mathrm{ND}=$ not detected; *Sampling points.

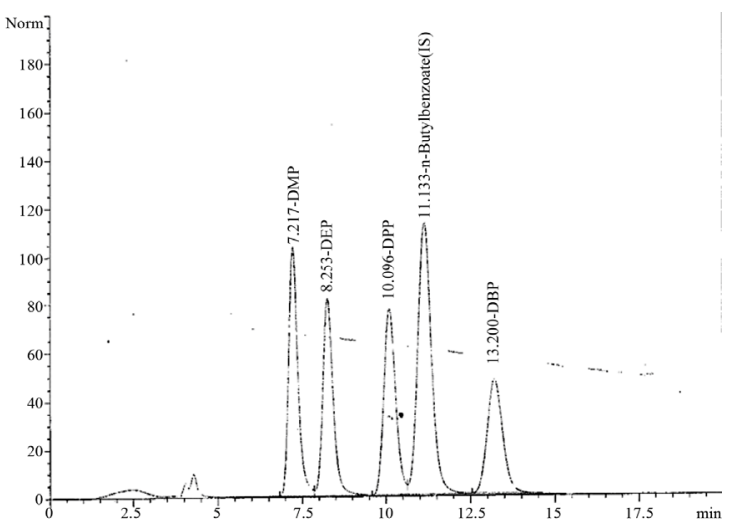

Figure 2. Representative chromatograph for phthalate ester standards and the internal standard.

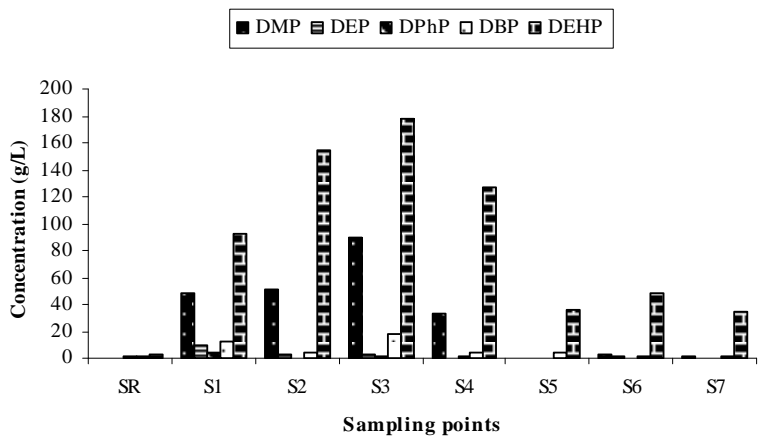

Figure 3. Multiple bar chart representing variation levels of phthalate esters in the study area with the sampling points.

phthalate ester plasticizers that may have leached from the plastic products containers, which the local resident 
commonly employed for domestic purposes upstream.

Table 2 showed the mean concentrations of phthalate esters in the sewage stream $\left(\mathrm{S}_{1}-\mathrm{S}_{3}\right)$ the receiving stream $\left(\mathrm{S}_{4}-\mathrm{S}_{7}\right)$ and the reference samples for the entire period of six weeks. For the sewage samples, the values ranged from $48.69 \mu \mathrm{g} / \mathrm{L}$ to $88.99 \mu \mathrm{g} / \mathrm{L}$ for dimethyl phthalate, $2.11 \mu \mathrm{g} / \mathrm{L}$ to $9.78 \mu \mathrm{g} / \mathrm{L}$ for diethyl phthalate, Not Detected to $4.57 \mu \mathrm{g} / \mathrm{L}$ for diphenyl phthalate, $3.92 \mu \mathrm{g} / \mathrm{L}$ to $17.32 \mu \mathrm{g} / \mathrm{L}$ for dibutyl phthalate and $93.09 \mu \mathrm{g} / \mathrm{L}$ to $178.17 \mu \mathrm{g} / \mathrm{L}$ for diethylhexyl phthalate. The expected trend for the concentration of the phthalate esters is that the level of phthalates in the sewage effluents stream will be decreasing downstream [26]. However, a cursory survey of the dominant phthalate esters levels in the sewage effluent stream shows the reverse of the expected trend as shown in Figure 2. This could likely be attributed to complexation of phthalate esters with various drugs and other chemical substances present as solute in the sewage system. These solutes could mask the phthalate esters and thus reduce the detectable level of these phthalates. This observation is substantiated by the fact that it has been discovered that complexes formed between solutes and phthalates ester solvents are likely to be of Van der Waal type perhaps augmented by dipoletype interaction and hydrogen bond acid solutes [29]. The complexation of phthalate esters with various chemical solvents has been investigated, for example, the effect of $\beta$-cyclodexterin on complexation of phthalate ester had been traced to the formation of inclusion complex between the two compounds [30]. Formation of complex product insoluble in common organic solvent formed by the reaction of some phthalates and polyvinyl pyrolidone (PVP) in ethanol and aqueous medium [31] is another fact that lays more credence to the observed trend.

However, the interaction of phthalate esters is weak and of Van der Waal type which contributes to the gradual decomplexation of phthalate ester observed. This decomplexation is suspected to be enhanced by aqueous dilution, and this occurs downstream as sewage effluents from the halls of residence join that from the hospital wards laden with drugs and other chemicals at the collection tank and gradually continues to mix progressively downstream. The contribution of all these factors is believed to have strongly contributed to the observed trend (Figure 3) in contrast to the expected trend in the sewage stream $\left(\mathrm{S}_{1}-\mathrm{S}_{3}\right)$.

For the samples from the receiving stream, the values ranged from not detected (ND) to $33.40 \mu \mathrm{g} / \mathrm{L}$ for dimethyl phthalate, ND to $0.72 \mu \mathrm{g} / \mathrm{L}$ for diethyl phthalate, ND to $1.93 \mu \mathrm{g} / \mathrm{L}$ for diphenyl phthalate, $1.41 \mu \mathrm{g} / \mathrm{L}$ to 4.37 $\mu \mathrm{g} / \mathrm{L}$ for DBP and $34.92 \mu \mathrm{g} / \mathrm{L}$ to $127.47 \mu \mathrm{g} / \mathrm{L}$ for diethylhexyl phthalate (Table 2). At sampling point $4\left(\mathrm{~S}_{4}\right)$, considering the level of dilution (about 100 fold dilution) that occurs when the sewage effluent stream joins, Oluju- oro stream (the Receiving stream) was expected to be very much lower than that of sewage samples. However, the determined concentrations of phthalate esters were higher than expected. This observation can no doubt be equally attributed to decomplexation of phthalate-solute complexes as earlier explained.

At point $S_{5}$, the observed levels of phthalate esters were lower than that of $\mathrm{S}_{4}$. This is in agreement with the result obtained by [26]. The reasons could be attributed to adsorption of phthalates on the sediment [32] and biodegradation of the phthalates by some micro-organism $[18,33]$. At point $\mathrm{S}_{6}$ however, higher concentrations of phthalate esters were detected. This increasing trend corresponds to the farming and recreational activities occurring within the vicinity of this point. Tourists patronizing Agodi zoological garden, often pass empty plastic containers of drinks and other household waste within the vicinity of point $S_{6}$. This practice could have contributed to the unexpected increase in the level of phthalate esters at this point. Concentrations of phthalate esters were still noticeable at $S_{7}$, where the stream entered Oyo State fish pond.

Table 3 shows the group mean levels of phthalates in the sewage, receiving stream and reference samples. Paired t-test for test of significance was used in comparing the values for sewage and receiving stream with the reference values. The t-score values were shown in Table 4. The concentrations of phthalate esters in the sewage effluent stream for all the phthalate esters studied were significantly different from the respective values for the reference samples. For the receiving stream, the concentrations of dimethyl-, diethyl-, diphenyl- and dibutyl phthalates were not significantly different from the respective values for the reference samples, whereas the concentration of diethylhexyl phthalate was significantly different from that of the reference sample.

However, a test of significance between the total phthalate in the receiving stream and that of the reference sample confirmed that there is a significant difference

Table 3. Group mean levels of phthalates in the sewage, receiving stream and reference samples.

\begin{tabular}{|c|c|c|c|}
\hline \multicolumn{4}{|c|}{ Sampling sites } \\
\hline & Reference $S_{F}$ & ${ }_{\mathrm{R}}$ Sewage $\left(\mathrm{S}_{1}-\mathrm{S}_{3}\right)$ & Receiving stream $\left(\mathrm{S}_{4}-\mathrm{S}_{7}\right)$ \\
\hline $\mathrm{DMP}(\mu \mathrm{g} / \mathrm{L})$ & ND & $62.81 \pm 18.53$ & $9.17 \pm 14.02$ \\
\hline $\mathrm{DEP}(\mu \mathrm{g} / \mathrm{L})$ & ND & $4.74 \pm 3.57$ & $0.18 \pm 0.31$ \\
\hline $\mathrm{DPhP}(\mu \mathrm{g} / \mathrm{L})$ & ND & $2.05 \pm 1.80$ & $0.48 \pm 0.84$ \\
\hline $\mathrm{DBP}(\mu \mathrm{g} / \mathrm{L})$ & $1.99 \pm 1.69$ & $11.40 \pm 5.58$ & $2.84 \pm 1.21$ \\
\hline DEHP $(\mu \mathrm{g} / \mathrm{L})$ & $2.69 \pm 2.04$ & $41.92 \pm 35.85$ & $1.72 \pm 38.35$ \\
\hline Total $(\mu \mathrm{g} / \mathrm{L})$ & $4.68 \pm 1.69$ & $220.87 \pm 40.94$ & $74.39 \pm 40.86$ \\
\hline
\end{tabular}

Concentrations are mean values \pm standard deviation for $\mathrm{n}=6$; $\mathrm{ND}=$ not detected. 
Table 4. t-score values for test of significance.

\begin{tabular}{ccc}
\hline \multicolumn{3}{c}{ Sampling sites } \\
\hline & Sewage $\left(\mathrm{S}_{1}-\mathrm{S}_{3}\right)$ & Receiving stream $\left(\mathrm{S}_{4}-\mathrm{S}_{7}\right)$ \\
\hline $\mathrm{DMP}(\mu \mathrm{g} / \mathrm{L})$ & 8.305 & 1.603 \\
$\operatorname{DEP}(\mu \mathrm{g} / \mathrm{L})$ & 3.258 & 1.417 \\
$\operatorname{DPhP}(\mu \mathrm{g} / \mathrm{L})$ & 2.996 & 1.409 \\
$\operatorname{DBP}(\mu \mathrm{g} / \mathrm{L})$ & 3.956 & 1.002 \\
$\operatorname{DEHP}(\mu \mathrm{g} / \mathrm{L})$ & 9.615 & 3.769 \\
\hline
\end{tabular}

between the aggregate level of phthalate esters in the receiving stream and that of the reference sample. It is therefore obvious that the bulk of phthalate esters pollution load on the receiving stream comes from di-(2-ethyl hexyl) phthalate. This is not unexpected as the main plasticizer used for most PVC medical devices is diethilhexyl phthalate [18].

The results of this study show that there is a possible negative impact of the sewage effluents on the receiving stream and possibility of deleterious effects of the phthalates on aquatic biota and people that depend on the receiving stream for fishing and recreational purposes. This observation is noteworthy as some of phthalate esters are endocrine disruptors and affect the development of the male reproductive system and production of normal sperm in young animals [34], while majority are carcinogenic, teratogenic and mutagenic organic pollutants $[25,35]$.

The pollution data obtained for the receiving stream in this study are much higher than those reported for rivers in the developed countries polluted with industrial sewage and chemicals [18,36,37]. Furthermore, values obtained in this study from the receiving stream are at least $10^{3}$ much higher than the water criteria of $3 \mu \mathrm{g} / \mathrm{L}$ recommended by the US Environmental Protection Agency for the protection of fish and other aquatic organisms in water [38]. The values are also higher than Suggested No-Adverse Effect Level of 7.5 - $38.5 \mu \mathrm{g} / \mathrm{L}$ for drinking water [26]. This is environmentally significant as the stream flows directly into Oyo State fish pond (Figure 1) where commercial fish farming is practiced.

\section{Conclusion and Recommendations}

The evaluation of the efficiency of the sewage treatment plant in removing or reducing the high concentration of phthalate esters in the hospital effluents is low. This was indicated in this study where high levels of the phthalate esters were found in the treatment effluent samples from the sewage plant and the samples from the receiving river. The situation is further compounded by the fact that receiving river empties into Oyo State fish pond where commercial fish farming is at present being practiced.
This poses health risk to consumer of the fish sourced from the pond. Therefore, there is an urgent need for the authorities in charge of the hospital to upgrade the sewage treatment facility so as to improve its efficiency, thereby reducing the pollution load of the effluent discharged into the surrounding river. Also, the state environmental agency needs to develop a routine monitoring programme in order to ensure that the levels of this pollutants discharged into the aquatic ecosystem are in agreement with the international standards.

\section{REFERENCES}

[1] B. C. Blount, K. E. Milgram, M. J. Silva, N. A. Malek, J. A. Reidy and L. L. Needham, "Quantitative Detection of Eight Phthalate Metabolites in Human Urine Using HPLC-APCI-MS/M,” Analytical Chemistry, Vol. 72, No. 17, 2000, pp. 4127-4134. doi:10.1021/ac000422r

[2] R. W. Moore, T. A. Rudy, T. Lin, K. Ko and R. E. Peterson, "Abnormalities of Sexual Development in Male Rats Uterus and Lactational Exposure to the Antiandrogenic Plasticizers Di-(2-Ethylhexyl) Phthalate,” Environmental Health Perspectives, Vol. 109, 2001, pp. 229-237. doi:10.1289/ehp.01109229

[3] M. L. Ward, G. Bitton and T. Townsend, "Heavy Metal Binding Capacity (HMBC) of Municipal Solid Waste Landfill Leachates," Chemosphere, Vol. 60, No. 2, 2005, pp. 206-215. doi:10.1016/j.chemosphere.2004.12.054

[4] M. Ema, E. Miyawaki and K. Kawashima, "Effects of Dibutyl Phthalate on Reproduction Function in Pregnant a Pseudo Pregnant Rats,” Reproductive Toxicology, Vol. 14, No. 1, 2000, pp. 13-19. doi:10.1016/S0890-6238(99)00066-0

[5] I. Colon, D. Caro, C. J. Bourdony and O. Rasario, "Identification of Phthalate Esters in the Serum of Young Puerto Rican Girls with Premature Breast Development,” Environmental Health Perspectives, Vol. 108, No. 9, 2000, pp. 895-900. doi:10.1289/ehp.00108895

[6] S. H. Swan, K. M. Main, F. Liu and S. L. Stewart, "Decrease in Anogenital Distance among Male Infants with Prenatal Phthalate Exposure," Environmental Health Perspectives, Vol. 113, No. 8, 2005, pp. 1056-1061. doi:10.1289/ehp.8100

[7] J. S. Fisher, "Human Testicular Dysgenesis Syndrome: A Possible Model Using In-Utero Exposure of the Rat to Dibutyl Phthalate," Human Reproduction, Vol. 18, No. 7, 2003, pp. 1383-1394. doi:10.1093/humrep/deg273

[8] S. M. Duty, M. J. Silva, D. B. Barr, J. W. Brock, L. Ryan, Z. Chen, R. F. Herrick, D. C. Christiani and R. Hauser, "Phthalate Exposure and Human Semen Parameters," Epidemiology, Vol. 14, No. 3, 2003, pp. 269-277. doi:10.1097/01.EDE.0000059950.11836.16

[9] R. Rozati, P. P. Reddy, P. Reddanna and R. Mujtaba, "Role of Environmental Estrogens in the Deterioration of Male Factor Fertility,” Fertility and Sterility, Vol. 78, No. 6, 2002, pp. 1187-1194. doi:10.1016/S0015-0282(02)04389-3

[10] G. Latini, “In-Utero Exposure to Di-(2-ethylhexyl) Phtha- 
late and Human Pregnancy Duration,” Environmental Health Perspectives, Vol. 111, No. 4, 2003, pp. 17831785. doi:10.1289/ehp.6202

[11] J. J. K. Jaakkola, L. Oie and P. Nafstad, “Interior Surface Materials in the Home and the Development of Bronchial Obstruction in Young Children in Oslo, Norway," American Journal of Public Health, Vol. 89, No. 2, 1999, pp. 188-192. doi:10.2105/AJPH.89.2.188

[12] J. A. Hoppin, R. Ulmer and S. J. London, "Phthalate Exposure and Pulmonary Function," Environmental Health Perspectives, Vol. 112, No. 5, 2004, pp. 571-574. doi:10.1289/ehp.6564

[13] C. G. Bornehag, J. Sundell and C. J. I. Weschler, "The Association between Asthma and Allergic Symptoms in Children and Phthalates in House Dust: A Nested CaseControl Study," Environmental Health Perspectives, Vol. 112, No. 14, 2004, pp. 1393-1397. doi:10.1289/ehp.7187

[14] K. Kato, M. J. Silva, L. L. Needham and A. M. Calafat, "Determination of 16 Phthalate Metabolites in Urine using Automated Sample Preparation and On-Line PreConcentration/High Performance Liquid Chromatography/Tandem Mass Spectrometry," Analytical Chemistry, Vol. 77, No. 9, 2005, pp. 2985-2991. doi:10.1021/ac0481248

[15] European Environmental Agency (EEA), “Comparative Research in Endocrine Disrupters, Phylogenetic Approach and Common Principles Focusing on Androgenic/ Antiandrogenic Compounds (COMPRENDO)," Copenhagen, 2005.

[16] M. J. Silva, J. A. Reidy, E. Samander, A. R. Herbert, L. L. Needham and A. M. Calafat, "Detection of Phthalates Metabolitesin Human Saliva," Archives of Toxicology, Vol. 79, No. 11, 2005, pp. 647-652. doi:10.1007/s00204-005-0674-4

[17] G. Rock, R. Labow and M. Tochi, "Distribution of Di(2-ethyl hexyl) Phthalates and Products in Blood and Blood Components,” Environmental Health Perspectives, Vol. 65, 1986, pp. 309-316.

[18] F. Zeng, K. Cui, A. Xie, M. Liu and Y. Li, “Occurrence of Phthalate Esters in Water and Sediment of Urban Lakes in a Subtropical City, Guangzhou South China," Environment International, Vol. 34, No. 3, 2008, pp. 372380.

[19] T. L. Swan and J. Davis, "Mechanisms of Phthalate Esters Toxicity in the Female Reproductive System," Environmental Health Perspectives, Vol. 11, 2003, pp. 139145.

[20] O. S. Fatoki and A. Noma, "Solid Phase Extraction Method for Selective Determination of Phthalate Esters in the Aquatic Environment," Water, Air \& Soil Pollution, Vol. 140, No. 1-4, 2002, pp. 85-98. doi:10.1023/A:1020134707450

[21] W. W. Huber, B. Crasl-Kraupp and R. Schulte-Hermann, "Hepatocarcinogenic Potential of DEHP in Rodents and Its Implications on Human Risk," Critical Review in Toxicology, Vol. 26, 1996, pp. 365-481.

[22] J. Vessman, and G. Reitz, "Determination of Di(ethylhexyl) Phthalate in Human: Plasma and Plasma Proteins by Electron Capture Gas Chromatography,” Journal of
Chromatography, Vol. 100, No. 1, 1974, pp. 153-163. doi:10.1016/S0021-9673(00)86049-5

[23] M. J. Bauer and R. Herrmann, "Estimation of the Environmental Contamination by Phthalic Acid Esters Leaching from Household Wastes," Science of the Total Environment, Vol. 208, No. 1-2, pp. 49-57. doi:10.1016/S0048-9697(97)00272-6

[24] A. O. Ogunfowokan, N. Torto, A. A. Adenuga and E. K. Okoh, "Survey of Level of Phthalate Ester Plasticizers in a Sewage Lagoon Effluent and a Receiving Stream,” Environmental Monitoring and Assessment, Vol. 118, No. 1-3, 2006, pp. 457-480. doi:10.1007/s10661-006-1500-z

[25] O. S. Fatoki and A. O. Ogunfowokan, "Procedural CleanUp Technique for Determination of Phthalate Esters in an Aquatic Environment," International Journal of Environmental Studies, Vol. 44, No. 4, 1993, pp. 237-243. doi:10.1080/00207239308710864

[26] O. S. Fatoki and A. O. Ogunfowokan, "Determination of Phthalate Ester Plasticizers in the Aquatic Environment of South Western Nigeria,” Environment International, Vol. 19, No. 3, 1993, pp. 619-623. doi:10.1016/0160-4120(93)90314-8

[27] M. Vitali, M. Guidotti, G. Macilenti and C. Cremisini, "Phthalate Esters in Freshwaters as Markers of Contamination Sources: A Site Study in Italy," Environment International, Vol. 23, No. 3, 1997, pp. 337-347. doi:10.1016/S0160-4120(97)00035-4

[28] A. Bjorseth, J. Knutzen and J. Skei, "Determination of Polycyclic Aromatic Hydrocarbons in Sediments and Mussel from Saudafjoid, W. Norway, by Glass Capillary Gas Chromatography," Science of the Total Environment, Vol. 13, 1979, pp. 71-89. doi:10.1016/0048-9697(79)90018-4

[29] G. Park and F. Poole, "Solvation in Weak Complexing n-Octyl Phthalate and n-Octylterachlorophthalate Solvent by Gas Chromatography,” Journal of Chromatography A, Vol. 726, No. 1-2, 1996, pp. 141-151. doi:10.1016/0021-9673(95)01061-0

[30] K. Sreenivasan, "Effect of Blending $\beta$-Cyclodextrin with Poly(vinyl chloride) on the Leaching of Phthalate Ester of Hydrophilic Medium,” Journal of Applied Polymer Science, Vol. 95, No. 13, 1998, pp. 2089-2093.

[31] V. Kuma and T. Y. Yang, "Interpolymer Complexation: Preparation and Characterization of a Polyvinyl Acetate Phthalate-Polyvinyl Pyrrolidone (PVAP-PVP) Complex," International Journal of Pharmaceutics, Vol. 188, No. 2, 1999, pp. 221-232. doi:10.1016/S0378-5173(99)00223-9

[32] E. Yuwantini, N. Hata and S. Taguchi, "Behaviour of Di (2-Ethyl Hexyl) Phthalate Discharged from Domestic Wastes Water in Aquatic Environment,” Journal of Environmental Monitoring, Vol. 8, 2006, pp. 191-196. doi:10.1039/b509767c

[33] K. Hashizume, J. Kanya, C. Toda, T. Yasui and H. Nagano, "Phthalate Esters Detected in Various Water Samples and Biodegradation of the Phthalates by Microbes Isolated from River Water," Biological and Pharmaceutical Bulletin, Vol. 25, No. 2, 2002, pp. 209-214. doi:10.1248/bpb.25.209

[34] Food and Drug Adminisration (FDA), "FDA Public 
Health Notification: PVC Devices Containing the Plasicizers DEHP,” 2002.

http://www.fda.gov/cdrh/safety/dehp.html

[35] J. A. Thomas, D. B. Wienc Kowsi, B. A. Gillies, M. J. Thomas and E. J. Youkillis, "Effects of Phthalic Acid Esters (PAEs) on the Neonates and Aspect of Teragogenic Actions," Environmental Health Perspectives, Vol. 63, 1995, pp. 243-248.

[36] S. Mori, "Identification and Determination of Phthalate Esters in River Water by High Performance-Liquid Chro- matography," Journal of Chromatography, Vol. 129, No 22, 1976, pp. 53-60. doi:10.1016/S0021-9673(00)87767-5

[37] H. Fromme, T. Kuchler, T. Oho, K. Pilz, J. Miller and A. Wenzel, "Occurrence of Phthalates and Bisphenol in the Environment,” Water Research, Vol. 36, No. 6, 2002, pp. 1429-1438. doi:10.1016/S0043-1354(01)00367-0

[38] USEPA (United States Environmental Protection Agency), “Water Quality Standards Handbook: Chapter 3,” US Environmental Protection Agency, Office of Water, Washington DC, 1994. 